\title{
USING PRE-OXIDATION TECHNIQUE TO MINIMIZE DISINFECTION BY-PRODUCTS IN SURFACE WATER TREATMENT
}

\author{
Abd El-Razek, T, M. A. ${ }^{(1)}$; Meligi G, A. ${ }^{(2)}$ and El-Sayed, W, H. ${ }^{(3)}$ \\ 1) Dept. of Env. Basic Science, Institute of Environmental Studies and \\ Research, Ain Shams University 2) Dept. of Organic Chemistry, Faculty of \\ Science, Ain Shams University 3) Holding Company for Water and \\ Wastewater, Egypt
}

\begin{abstract}
Reactions between chlorine disinfectants, total organic carbon (TOC), and other chemicals in water form a series of disinfection by-products (DBPs), including trihalomethanes (THMs) that are toxic and suspected carcinogens. This paper aims at reducing DBPs formation potential through the degradation of the precursors using pre-oxidation. First, a survey analysis for five different water treatment plants (WTPs) was carried out to determine the most polluted site with TOC and THMs afterward, the efficiency of three different oxidants (potassium peroxy-mono-sulfate, potassium permanganate, and hydrogen peroxide) was tested under different conditions of $\mathrm{pH}$, oxidant concentration and contact time. Optimum values for the mentioned conditions were used to achieve the maximum reduction for THMs in Mostorod-WTP which recorded the highest concentration of TOC and THM. THMs reduction efficiency of $54 \%, 67 \%$, and $99 \%$ was achieved by using potassium peroxymono-sulfate, potassium permanganate, and hydrogen peroxide, respectively. In conclusion, hydrogen peroxide was the best in reducing THMs.

Keywords: DBPs, Natural organic matter, potassium permanganate, potassium peroxy-mono-sulfate, hydrogen peroxide, drinking water, pre-oxidation.
\end{abstract}


J. Environ. Sci.

Institute of Environmental Studies and Research - Ain Shams University

\section{INTRODUCTION}

Delivering safe drinking water to consumers is the main target of water treatment plants (WTPs), and can be achieved through choosing the most convenient technology to reach the desired quality. Disinfection is a vital process in surface water purification as it inactivates pathogens that cause common waterborne diseases such as typhoid, cholera, dysentery and diarrhea (Abdelhalim et al., 2014).

Although disinfection is very important to the public health, the disinfectant itself poses a hidden threat by forming Trihalomethanes (THMs) through its reaction with Natural Organic Matter (NOM). (Filella, 2009).

Chlorine is used as a primary disinfectant in water treatment and to provide a stable disinfectant residual and to assure delivery of safe water throughout the distribution network. However, this character of chlorine makes it most suitable as a disinfectant. It also means that it is more prone to DBP formation because it retains more contact time with organic matter, which was not, removed during coagulation and filtration processes. (EPA, 2011).

Clark. (1998) reported that the formation of THMs in drinking water has been shown to be a function of various water quality parameters and chlorination conditions. THMs formation is one of the slowest known reactions in water treatment and a number of important factors influence this reaction. These include residence time, $\mathrm{pH}$, temperature, bromide ion concentration, chlorine dosage, type of organic precursor and the Total Organic Carbon (TOC). Many efforts have been done to overcome this 
critical issue through the reduction of the organic content in raw water by different methods including: activated carbon (Symons et al., 1981) and oxidation (using either ozone or chlorine dioxide as the oxidant), for the degradation of the organic matter to reduce the THMs formation potential of the raw water (Glaze et al., 1987 and George et al., 2008).

In this paper, the addition of an initial oxidant (potassium peroxy-monosulfate, potassium permanganate, and hydrogen peroxide) will be applied before the pre-chlorination to minimize the organic load in the source water to avoid the formation of carcinogenic DBPs in drinking water and these oxidants.

\section{MATERIALS AND METHODS}

2.1 Survey analysis for TOC and THMs: A survey study was carried out to determine the concentrations of THMs in treated water and TOC in raw and treated waters from five WTPs in Greater Cairo to reveal the most polluted sites, the analysis was done according to (APHA, 2012).

The selected WTPs were (El-Tebben, Mostorod, Rod El-Farag, El-Fustat and Shoubra El-Khaimah) the total quantity produced as drinking water by these WTPs in sum is about 4,500,000 $\mathrm{m}^{3} /$ day.

THMs were analyzed with a liquid-liquid extraction-gas chromatographic method adopted from EPA 551 and APHA 6232B and optimized for the laboratory conditions. A Varian 3800 GC (Mountain View, CA) with the linearized electron-capture detector. THM peaks were confirmed using GC-MS (HP-6890/5973). The total THM concentration, as 
used by EPA for reporting purposes, was determined by simple summation of individual components.

2.2 Treatment process description: The treatment process in the five mentioned WTPs is almost the same in sequence and techniques used starting by mechanical screening for blocking of large objects, followed by primary disinfection using chlorine gas for inactivation of pathogens, and then the optimum dose of aluminum sulfate coagulant is added to remove the particulates and reduce the organic load. Afterward, the water is subjected to rapid sand filters to remove the rest of the turbidity. As a final step postdisinfection is applied to assure residual chlorine in the produced water that protects it against any further pollution in the distribution networks.

2.3 Chlorine dose determination: In order to determine the chlorine dose, a breakpoint chlorination test (APHA, 2012 and March and Gual, 2007) is done to each batch of raw water sampled from Mostorod-WTP before starting the evaluation of different oxidants under different factors.

2.4 Pre-oxidation efficiency testing: In this section of the study, the effect of three different oxidants (potassium permanganate, hydrogen peroxide, and potassium peroxy-mono-sulfate) was studied by applying various conditions that affect the degradation of organic matter in raw water. The organic matter removal efficiency for the three oxidants under various conditions was determined through measuring THMs formed under the same working factors without oxidant addition. This value of THMs represents the maximum amount formed under the applied conditions eliminating the action of preoxidation. The procedure includes the addition of the determined optimum 
chlorine dose to raw water sample then left for six hours, to simulate the actual retention time for the disinfection in Mostorod-WTP after chlorine addition. The oxidation and decomposition of the organic matter were studied according to three different factors, which are; oxidant concentration (mg/l), $\mathrm{pH}$ and contact time (hours). The efficiency of the organic matter removal was determined through the equation (1)

Total THMs removal efficiency\%

$$
=\frac{\left(C_{\mathrm{o}}-C\right)}{C_{\mathrm{o}}}
$$

Where $\mathrm{C}_{\mathrm{o}}=$ Total THM without the action of oxidant $(\mu \mathrm{g} / \mathrm{l})$

$\mathrm{C}=$ Total THM after using the oxidant $(\mu \mathrm{g} / \mathrm{l})$

The procedures carried out to study different factors affecting the oxidation process of organic matter are presented in the following:

\subsubsection{Studying the effect of oxidant concentration on THMs reduction}

efficiency: In order to study the impact of oxidant concentration on THMs reduction efficiency, a series of different concentrations from the used oxidant (potassium permanganate, hydrogen peroxide or potassium peroxy-monosulfate) was used $(2,4,8,12,16$ and $20 \mathrm{mg} / \mathrm{l})$ through the addition of the equivalent volumes of a concentrated solution for the used oxidant. The oxidant was left in contact with the raw water in brown bottles for six hours then the optimum chlorine dose $(2 \mathrm{mg} / \mathrm{l})$ was added. The solution was left for six hours as contact time with the chlorine dose. The samples were dechlorinated and preserved till the analysis of THMs. Then the samples were analyzed for THMs (APHA, 2012) and the removal efficiencies were determined through equation (1). 
2.4.2 Effect of $\mathrm{pH}$ on THMs reduction efficiency: The impact of $\mathrm{pH}$ on THMs removal efficiency was studied. The $\mathrm{pH}$ value was adjusted to three different $\mathrm{pH}$ values using $1 \mathrm{~N} \mathrm{H}_{2} \mathrm{SO}_{4}$ and $1 \mathrm{~N} \mathrm{NaOH}$. The $\mathrm{pH}$ of raw water measured electrometrically using the $\mathrm{pH}$ meter (HACH (U.S.A), ECO 10). The used $\mathrm{pH}$ values were 4,7 and 10 using the optimum concentration of each oxidant that is found from the first step then the optimum chlorine dose is added which is $2 \mathrm{mg} / \mathrm{l}$; the raw water was left for six hours with the chlorine. The samples were de-chlorinated and preserved until the analysis of THMs. Then, the samples were analyzed for THMs (APHA, 2012) and the removal efficiencies were determined through equation (1).

\subsubsection{Effect of the oxidant contact time on THMs reduction efficiency: To} study the effect of contact time on the oxidation efficiency of the oxidants, retention times were $2,4,6,8,10$ and 12 hours using the optimum concentration of each oxidant then the optimum chlorine dose is added ( 2 $\mathrm{mg} / \mathrm{l})$. The raw water was left for a period of six hours with the chlorine dose. After that the samples were collected, de-chlorinated and preserved until the analysis of THMs and the removal efficiencies were determined through equation (1).

\section{RESULTS AND DISCUSSIONS}

3.1 Survey analysis for TOC and THMs: As mentioned in section $2.1 \mathrm{a}$ survey study carried out to determine the WTP site with higher TOC and THMs values and the data are presented in Figure (1 and 2). 


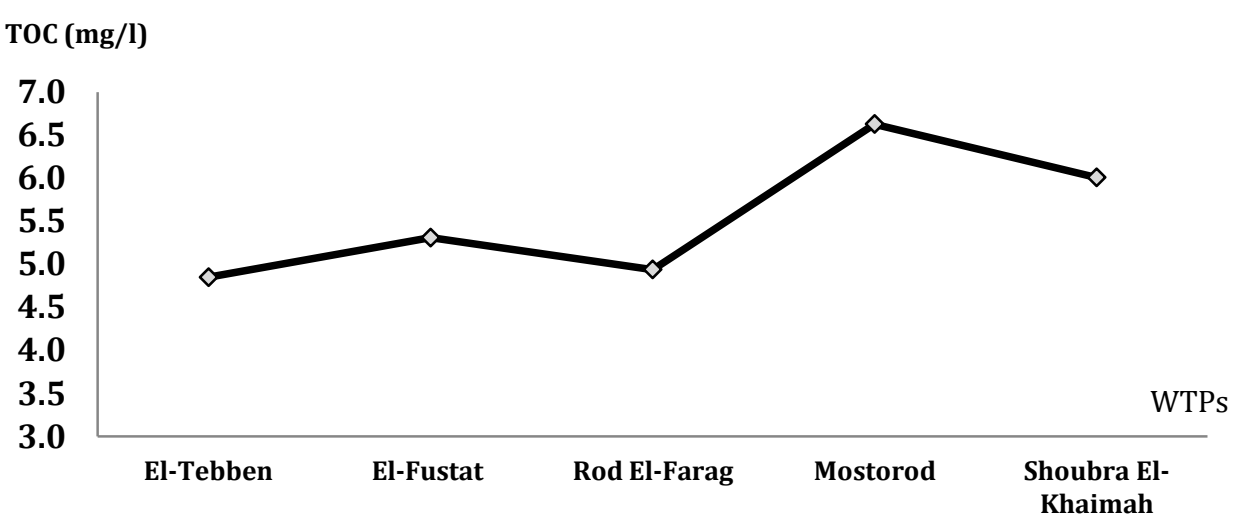

Figure (1): Concentration of TOC (mg/l) in Greater Cairo WTPs raw water.

As presented in Figure (1), the amount of organic matter TOC is maximum at Mostorod WTP with $6.63 \mathrm{mg} / \mathrm{l}$; this could be explained by the presence of many companies such as (petroleum pipelines, Cairo Petroleum, Al Delta for Iron and steel and Cables) alongside the intake of Mostorod which may spill some of its discharge directly into the mainstream causing this unfavorable increase in organic carbon.

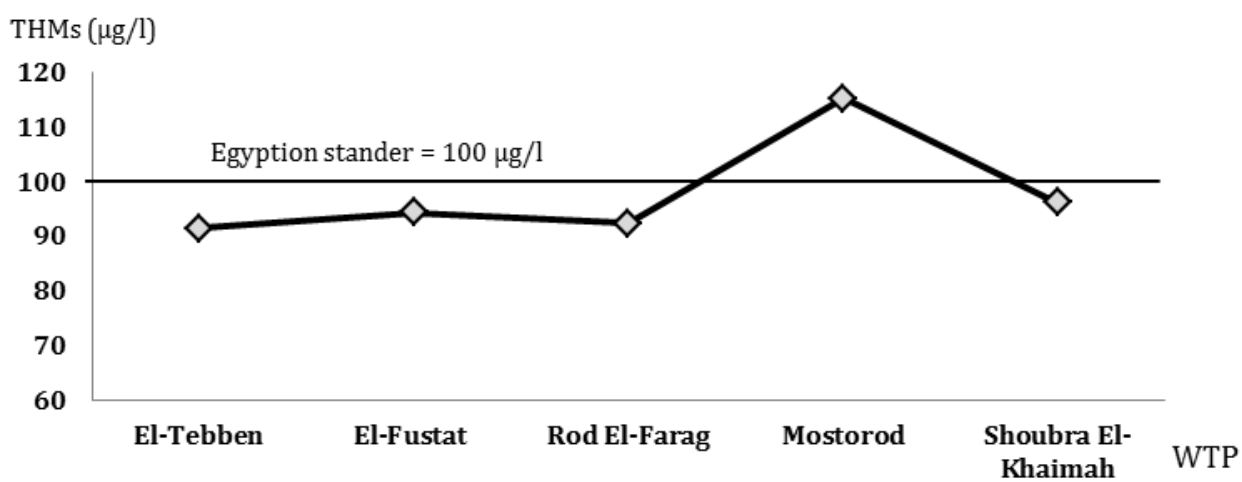

Figure (2): Concentration of THMs $(\mu \mathrm{g} / \mathrm{l})$ in drinking water for Greater Cairo WTPs. 
As shown in Figure (2), the values of THM for the tested WTPs are within the Egyptian limits for drinking water quality stated by decree no. 458 in 2007 except Mostorod WTP that has the maximum THM of $115.2 \mu \mathrm{g} / \mathrm{l}$. This can be due to the increase in organic load (TOC) in the intake.

Saidan et al. (2013) reported that the formation of THMs is strongly dependent on the amount of naturally present humic substances (Humic and Fulvic acids). In other words, DBPs increase by TOC elevation in presence of free chlorine residuals, which is also clear from the data in Figure (1 and 2).

The above results prove that the raw water of Mostorod-WTP intake is the most polluted site detected in the survey with the highest THMs precursor. Therefore, the next experiments will be conducted on MostorodWTP raw water to investigate the effect of pre-oxidation on the amount of produced THMs.

3.2 Effect of Pre-oxidation: The effect of pre-oxidation with potassium peroxy-mono-sulfate $\left(\mathrm{KHSO}_{5}\right)$, potassium permanganate $\left(\mathrm{KMno}_{4}\right)$ and hydrogen peroxide $\left(\mathrm{H}_{2} \mathrm{O}_{2}\right)$ on the amount of produced THMs was investigated according to the procedures mentioned in materials and methods section and the results are presented and discussed in the following:

\subsubsection{Effect of pre-oxidation on THMs formation.}

- Effect of oxidant concentration: The three used oxidants have different efficiencies on the reduction of THMs formed in water. It is clear in Figure (3) a maximum removal percent of $99.54 \%$ has been accomplished using peroxide with a dose of $20 \mathrm{mg} / \mathrm{l}$. Where at $12 \mathrm{mg} / \mathrm{l}$ dose THMs reduction was $97.06 \%$ which shows no significance difference between 20 and 12 
$\mathrm{mg} / \mathrm{l}$ peroxides doses, so it's more cost effective to apply peroxide dose of $12 \mathrm{mg} / \mathrm{l}$ during the application phase.

Petri et al., (2011) reported that hydrogen peroxide used a strong oxidant that long has been used in water treatment processes. Peroxide may generate a wide variety of free radicals $\left(\mathrm{OH}^{\circ}\right)$ and other reactive species that are capable of decomposing organic material.

Many literatures illustrated that hydrogen peroxide can be used as an independent treatment or as an improvement of existing physical or biological treatment processes, according to the situation (Ksibi, 2006). Hydrogen peroxide can be used alone (Millero \& Sotolongo, 1989); or with a catalyst such as iron $\left(\mathrm{Fe}^{2+}\right.$ or $\left.\mathrm{Fe}^{3+}\right)$ (Ganesan \& Thanasekaran, 2011); UV light (Venkatadri \& Peters, 1993) ozone $\left(\mathrm{O}_{3}\right)$ (Glaze, et al. 1987); catalytic autooxidation (Kotronarou et al., 1991); the alkali contribute to the reduction of the BOD/COD in the wastewater (Barker et al., 1990).

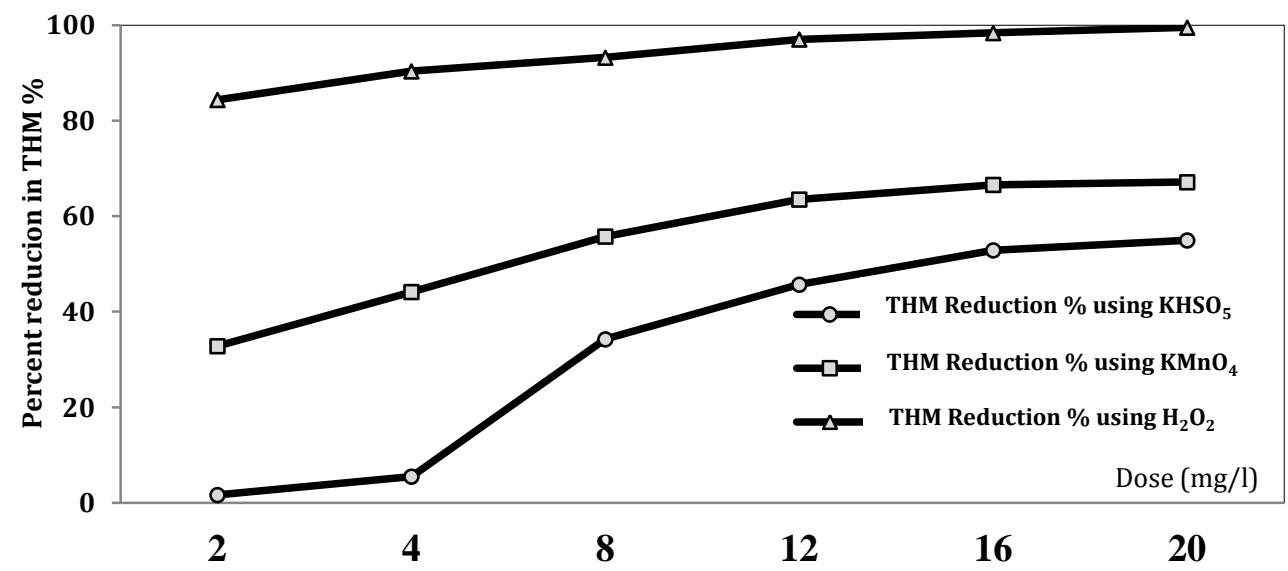

Figure (3): Effect of the oxidants doses on THMs concentration and reduction efficiency. 
Using permanganate, the maximum removal of THMs $(67.16 \%)$ has been reached at a dose of $20 \mathrm{mg} / \mathrm{l}$.

Singer et al., (1980) studied the application of potassium permanganate in waters collected in North Carolina and reported that when these waters had been pretreated with 2 to $10 \mathrm{mg} / \mathrm{l}$ potassium permanganate, before chlorination, less chloroform was produced, compared to the same waters treated with chlorine. They also mentioned that the potassium permanganate treatment doses used did not oxidize all the precursors, and its application alone, without moving the point of chlorination, would not reduce the THMs concentration to the desired levels. The combined treatment changes, whereas, along with improved coagulation would result in finished water that meets the THMs regulation.

The potassium peroxy-mono-sulfate molecule has recently attracted some attention in the removal of contaminants dissolved in water. Due to the potential oxidizing capacity of the radicals generated after its decomposition (Rivas et al., 2009).

Potassium peroxy-mono-sulfate has the lowest effectiveness in THMs reduction. The maximum removal percentage achieved for THMs is (54.96 $\%$ ) using a dose of $20 \mathrm{mg} / \mathrm{l}$.

It is obvious that the effective pre-oxidation by the used oxidants has a significant effect on the produced amount of THMs. This could be attributed to the ability of the three oxidants to decompose the organic matter, which decreases it and minimizes THMs formation potential and the available TOC that reacts with chlorine. 
Hydrogen peroxide is the most effective pre-oxidant. Using hydrogen peroxide as a pre-oxidant has a noticeable ability to decrease THMs, which reflects the power of peroxide to minimize TOC.

- Effect of pH on THMs reduction efficiency: The chemical oxidation processes, $\mathrm{pH}$ plays a key role in decomposition of oxidant to generate free radicals. It also affects the formation of the species of transition metals and their availability for reaction with the oxidant (Ghanbari, and Moradi, (2017)).

Results presented in Figure 4 revealed that by decreasing the value of $\mathrm{pH}$ the reduction efficiency for THMs is increased due to the decomposition of the organic matter by oxidation is much more influenced in acidic medium.

Our findings are compatible with (Huang et al., 2016) who expressed that in acidic conditions, the degradation rate was enhanced markedly as the solution $\mathrm{pH}$ in the range $3.5-5$ while decreased considerably as the $\mathrm{pH}$ of the solution between 6 -8.4 (Huang et al., 2016).

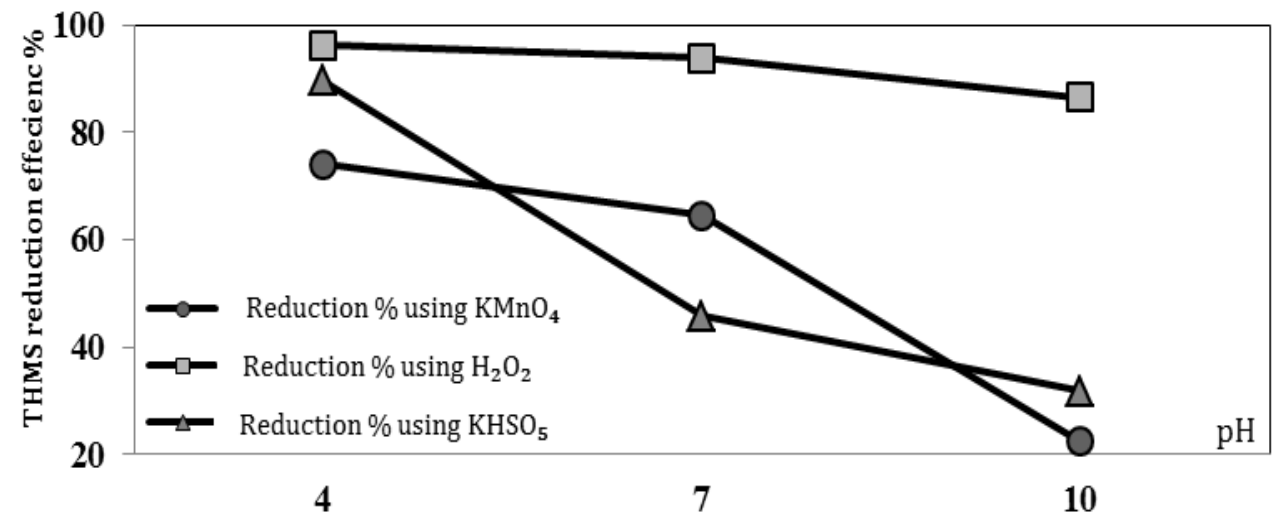

Figure (4): Effect of $\mathrm{pH}$ on reduction efficiency of oxidants on THMs in water, dose $20 \mathrm{mg} / \mathrm{l}$. 
Sang, (2013) concluded that at low $\mathrm{pH}$, the aqueous solution of potassium peroxy-mono-sulfate is relatively stable. The stability is affected adversely by higher $\mathrm{pH}$. Based on literature, potassium peroxy mono sulfate is considered as an acidic oxidant and the generation of $\mathrm{SO}_{4}{ }^{-}$can be facilitated at low $\mathrm{pH}$. In contrast, under basic condition was prone to decomposition without producing sulfate radicals and therefore decreased the degradation. The maximum removal of THMs (89.53\%) has been accomplished using PH 4 with a dose of $20 \mathrm{mg} / \mathrm{l}$ of peroxy-mono-sulfate. In addition, our results are compatible with Farren, (2003) as it was reported by his research that increasing the $\mathrm{pH}$ combined with the THMs rising.

Petri, et al (2011) reported that hydrogen peroxide reaction chemistry is complex, but potentially capable of degrading a wide range of organic contaminants depending on conditions. When catalyzed in water, hydrogen peroxide may generate a wide variety of free radicals. The strong standard reduction potential of this radical in the acidic solution and reduced in the alkaline $\left(\mathrm{E}^{\mathrm{o}}=2.59 \mathrm{~V}\right.$ at $\mathrm{pH} 0,1.64 \mathrm{~V}$ at $\left.\mathrm{pH} 14\right)$.

The hydrogen peroxide is showing the best reduction of $96.18 \%$ at $\mathrm{pH} 4$ whereas, both potassium permanganate and potassium peroxy-mono-sulfate show less efficiency. 
Effect of Time on THMs reduction efficiency: The removal tendency at different time intervals $(2,4,6,8,10$, and 12 hours $)$ is expressed graphically in Figure 5.

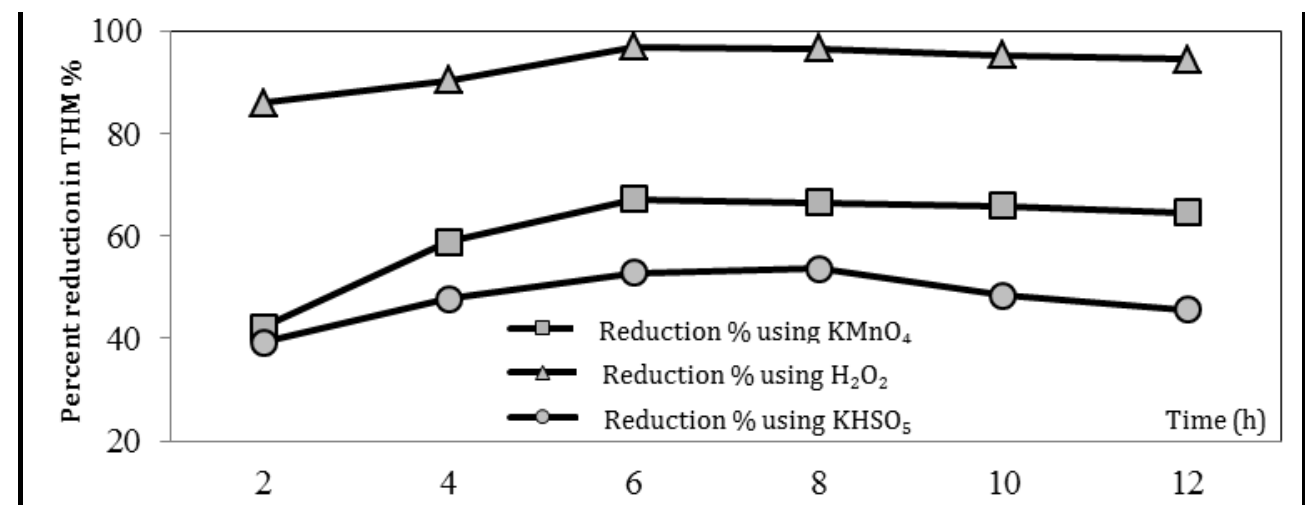

Figure (5): Effect of time on reduction efficiency of oxidants on THMs in water, dose $20 \mathrm{mg} / \mathrm{l}$.

By increasing the contact time the reduction efficiency increases until 6 hours, no significant decrease is noticed after this time. It is obvious from the Figure (5) maximum reduction of THMs was achieved using contact time of 6 hours for potassium permanganate and hydrogen peroxide whereas, potassium peroxy-mono-sulfate recorded a maximum removal by applying 8 hours retention time. This is due to as the reaction time increases the dissociation of organic matter rises, while further increment of time cause decrease in the removal efficiency of THMs this because the more time is applied to chlorine with the NOM it is more probability to form more THMs.

Farren, (2003) stated that THMs formation depends on several factors. THMs concentrations increase with rising contact time. For the free chlorine samples, as residence time increased, the THMs increased. Therefore, reducing the contact period to 0 or 3 hours would reduce THMs formation. 
Pignatello, (2006) stated that the effects of high concentrations of NOM may be mitigated by the addition of higher dosages of oxidant and longer reaction times.

\section{CONCLUSION}

The survey on Cairo water treatment plants reveals that Mostorod-WTP is the most polluted spot by organic matter with TOC concentration of 6.63 $\mathrm{mg} / \mathrm{l}$ for the raw water. In addition, Mostorod-WTP recorded the highest THMs concentration of $115.2 \mu \mathrm{g} / \mathrm{l}$. Pre-oxidation using potassium peroxymono-sulfate, potassium permanganate and hydrogen peroxide were carried out to investigate its effect on the formation of DBPs. Hydrogen peroxide achieved the maximum THMs removal of $99 \%$ using $\mathrm{pH} 4$, concentration 20 $\mu \mathrm{g} / \mathrm{l}$ and contact time 6 hours. It is recommended to use hydrogen peroxide as a pre-oxidant under the mentioned conditions to remove TOC and reduce the THMs formation potential of the raw water.

\section{REFERENCES}

Abdelhalim, N. H.; Imam, E. H. and Nour, M. H. (2014). Fate of Natural Organic Matter and Formation of Disinfection By-Products in a Conventional Water Treatment Plant. Proceedings of the Water Environment Federation, 2014(6), 2703-2718.

American Public Health Association, American Water Works Association, Water Environment Federation (APHA) (2012). Standard Methods for the Examination of Water and Wastewater, Rice, E.W., Baird, R.B., Eaton, A.D. L.S. Clesceri, L.S., Eds.; 22nd ed.; American Public Health Association: Washington, D.C. 
Barker, D. J.; Bull, A. R.; Osmond, C. and Simmonds, S. J. (1990). Fetal and placental size and risk of hypertension in adult life. Bmj, 301(6746), 259-262.

Clark, R. M. (1998). Chlorine Demand and T-THM Formation Kinetics: a Second-Order Model. Jour. Environ. Eng. ASCE, 124(1): 16-24.

EPA, (2011). The Environmental Protection Agency. Water treatment manual: disinfection .report. Johnstown Castle, Co. Wexford, Ireland. Page 187.

Farren, E. A. (2003). Reducing trihalomethane concentrations by using chloramines as a disinfectant (Doctoral dissertation, Worcester Polytechnic Institute).

Filella, M. (2009). Freshwaters: which NOM matters?. Environmental Chemistry Letters, 7(1), 21-35.

Ganesan, R. and Thanasekaran, K. (2011). Decolourisation of textile dyeing Wastewater by modified solar Photo-Fenton Oxidation. International Journal of Environmental Sciences, 1(6), 1168.

George, P. A.; Thomas, P. T.; Dionysios, D. D. (2008). Chemical and microbial decontamination of pool water using activated potassium peroxymonosulfate, Water Research, 42, 2899 - 2910.

Ghanbari, F. and Moradi, M. (2017). Application of peroxymonosulfate and its activation methods for degradation of environmental organic pollutants: Review. Chemical Engineering Journal, 310, 41-62.

Glaze, W. H.; Joon-Wun, K. and Douglas H. C. (1987) "The chemistry of water treatment processes involving ozone, hydrogen peroxide and ultraviolet radiation. Ozone: Science and Engineering, 9(4), 335-352.

Huang, Y.; Wang, Z.; Fang, C.; Liu, W.; Lou, X. and Liu, J (2016) Importance of reagent addition order in contaminant degradation in an $\mathrm{Fe}(\mathrm{II}) / \mathrm{PMS}$ system, RSC Adv. 6.70271-70276.

Ksibi, M. (2006). Chemical oxidation with hydrogen peroxide for domestic wastewater treatment. Chemical Engineering Journal, 119(2), 161-165. 
Kotronarou, A.; Mills, G.; Hoffmann, M. R. (1991).Ultrasonic Irradiation of p-Nitrophenol in Aqueous Solution. the Journal of physical chemistry, 95(9), 3630.

March, J. G. and Gual, M. (2007). Breakpoint chlorination curves of greywater. Water Environment Research : A Research Publication of the Water Environment Federation, 79(8), 828-32.

Millero, F. J. and Sotolongo, S. (1989). The oxidation of Fe (II) with $\mathrm{H} 2 \mathrm{O} 2$ in seawater. Geochimica et Cosmochimica Acta, 53(8), 1867-1873.

Petri, B. G. ; Watts, R. J.; Teel, A. L.; Huling, S. G.; and Brown, R. A. (2011). Fundamentals of ISCO using hydrogen peroxide. In In situ chemical oxidation for groundwater remediation (pp. 33-88). Springer New York.

Pignatello, J. J.; Oliveros, E. and MacKay, A. (2006). Advanced oxidation processes for organic contaminant destruction based on the Fenton reaction and related chemistry. Critical reviews in environmental science and technology, 36(1), 1-84.

Rivas, J.; Gimeno, O.; Carbajo, M., and Borralho, T. (2009). Catalytic Decomposition of Potassium Monopersulfate. Influence of Variables. In Proceedings of World Academy of Science, Engineering and Technology. 57, 218-222.

Saidan, M.; Rawajfeh, K. and Fayyad, M. (2013). Investigation of factors affecting THMs formation in drinking water. American Journal of Environmental Engineering, 3(5), 207-212.

Sang, L. (2013). Chemical Decontamination of Outdoor Pool Water using Oxone ${ }^{\circledR}$ and the Impact of Nanoparticles from Personal Care Products (Doctoral dissertation, University of Cincinnati).

Singer, P. C.; Borchardt, J. H. and Colthurst, J. M. (1980). The effects of permanganate pretreatment on trihalomethane formation in drinking water. Journal of American Water Works Association,72(10) 573-578.

Symons, J. M.; Stevens, A. A.; Clark, R. M.; Geldreich, E. E.; Love, O. T. and DeMarco, J. (1981). Treatment techniques for controlling 
trihalomethanes in drinking water. EPA 600/2-81- 156, Final Report for U.S. EPA-DWRD, U.S. EPA, Cincinnati, OH.

Venkatadri, R. and Peters, R. W. (1993). Chemical oxidation technologies: ultraviolet light/hydrogen peroxide, Fenton's reagent, and titanium dioxide-assisted photocatalysis. Hazardous Waste and Hazardous mterials, 10(2): 107-149. doi:10.1089/hwm.1993.10.107.

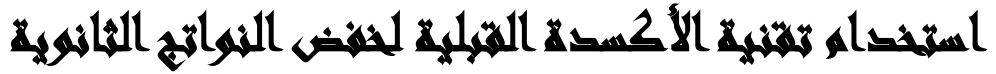 هيكي معالجة المياه السطيهية}

[1]

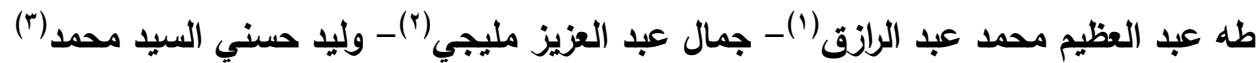

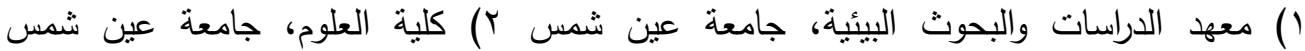

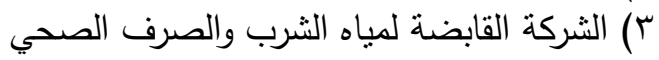

\section{المستخلئ}

إستخدام الكلور كمطهر ينتج عنه مواد ثانوية نتيجة لتفاعلة مع المواد العضوية الطبيعية

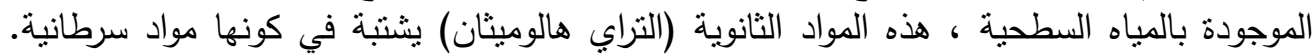

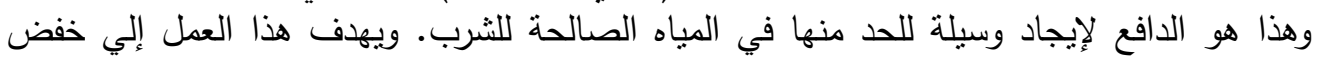

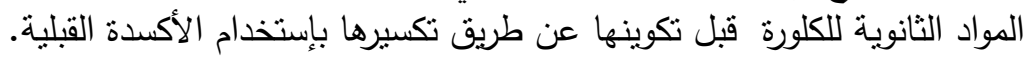
أولاً نم إجراء مسح تحليلي لخمس محطات مياه مختلفة لتحديد الموقع الأكثر تلوثنا بالكربون

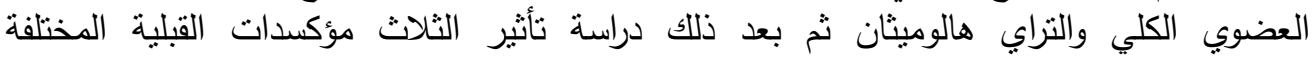

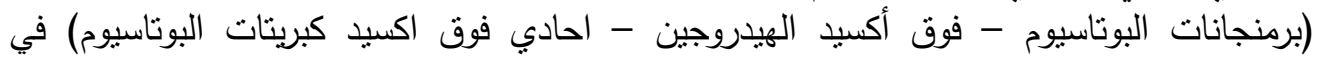

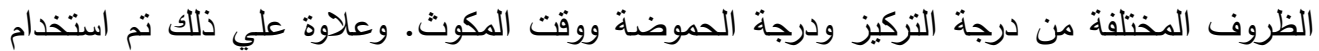

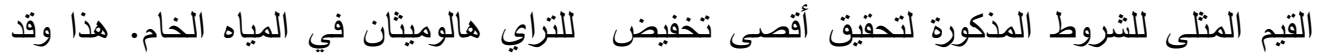

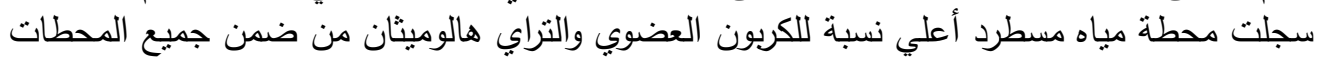

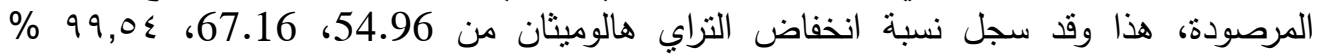

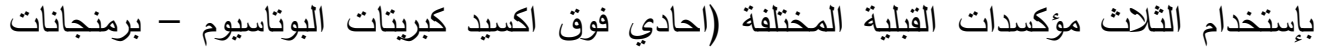

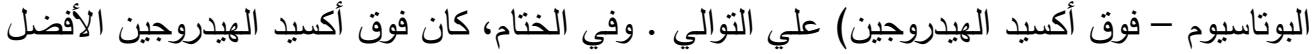

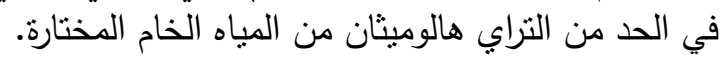

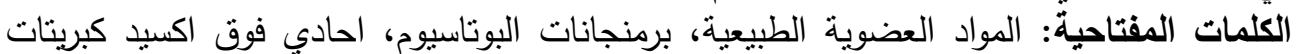
البوتاسيوم، فوق أكسيد الهيدروجين، النواتج الثانوية للنطهير ، مياه الثرب النيات والأكسدة القبلية. 